\title{
Poesia e fotografia: um caminho para o letramento literário
}

Mestra em Língua Portuguesa pela Universidade Estado de Mato Grosso, Campus Universitário de Sinop. Efetiva na disciplina de língua portuguesa na rede Estadual de Mato Grosso há 21 anos. Discente no Projeto de Pesquisa: "A pesquisa-ação no Norte do Mato Grosso: perspectivas da formação de

$-0002-9643-8415$

E-mail: dauhali@yahoo.com.br

Recebido em: 12/2/2019.

Aprovado em: $23 / 7 / 2019$.

ndereço:

Av. dos Ingass, 3001 - Jardim Imperial, Sinop, Mato

Grosso, CEP: 78555-000

\section{Poetry and photography: a path to literary literacy}

Patrícia Dauhali Clemente Guimarães ${ }^{1}$

Universidade do Estado de Mato Grosso, Faculdade de Educação e Linguagem, Sinop, MT, Brasil.

\section{RESUMO}

Este artigo centra-se no letramento literário, com base na inter-relação entre literatura e fotografia, as potencialidades poéticas da fotografia e da escrita para a educação, buscando uma política visual que conceba as imagens não como representação intacta de certa visibilidade, mas como possibilidades de criação de novas visualidades, na aproximação do real com a arte. Potencializando estudos da escrita, da imagem e da cultura na busca dos multiletramentos nas práticas pedagógicas das aulas de Língua Portuguesa no Ensino Fundamental. Para o aporte teórico, recorremos aos estudos de Barthes (1980), Candido (2011), Cosson (2014), Rojo (2012), Sorrenti (2009), Todorov (2009), Soares (2004), Kleiman (1995) e Sontag (2004), dentre outros. Com vistas às práticas de multiletramentos que auxiliem na formação de cidadãos capazes de expressarem e interpretarem, crítica e artisticamente, as ideias e visões em relação ao contexto que os cercam, bem como de se identificarem culturalmente, a partir do trabalho com a fotografia e a poesia haicaísta.

Palavras-chave: Fotografia. Poema. Letramento literário.

\section{ABSTRACT}

This article focuses on literary literacy, based on the interrelationship between literature and photography, the poetic potentialities of photography and writing for education, seeking a visual policy that conceives the images not as intact representation of a certain visibility, but as possibilities of creating new visualities, in the approximation of the real with art. Empowering studies of writing, image and culture in the search of multiletramentos in the pedagogical practices of Portuguese Language classes in elementary school. For the theoretical contribution, we used the studies of Barthes (1980), Candido (2011), Cosson (2014), Rojo (2012), Sorrenti (2009), Todorov (2009), Soares (2004), among others. With a view to multilevel practices that help in the formation of citizens capable of expressing and interpreting, critically and artistically, the ideas and visions regarding the context that surrounds them, as well as of identifying themselves culturally, from the work with photography and haiku poetry.

Keywords: Photography. Poem. Literary literacy. 


\section{Introdução}

$\mathrm{N}^{\mathrm{a}}$

tentativa de não conceber a literatura como um conteúdo independente dentro das práticas pedagógicas da disciplina de Língua Portuguesa, como algo isolado dos estudos sobre leitura, produção textual e análise linguística é que tivemos a preocupação de propor este artigo voltado ao estudo do gênero poético e fotográfico, visando atender às condições de produção e à circulação desses gêneros partindo de eventos de letramento que constituem o cotidiano dos educandos.

Ao abordar as relações entre ensino-aprendizagem no âmbito escolar, estamos falando sobre o processo de apropriação de saberes por parte do aluno, não somente nos seus diferentes níveis, mas também no que se refere às diferentes culturas e realidades com as quais ele tem contato.

Saber estabelecer relações entre o currículo formal e a realidade cotidiana é um dever de todos os educadores envolvidos com o processo de aprendizagem, proporcionando na sala de aula um espaço voltado para os objetivos gerais do Ensino Fundamental indicados pelos Parâmetros Curriculares Nacionais no que concerne à análise e interpretação crítica dos alunos.

Por esse caráter polissêmico e dinâmico, a presença da literatura em sala de aula se torna imprescindível. Através dela o aluno vivencia a linguagem nos seus múltiplos aspectos e tem a possibilidade de compreender o mundo por meio das inúmeras vozes que o texto deixa aflorar.

De modo geral, a poesia e seu estudo são considerados pela maioria dos alunos como algo "difícil", sem sentido e, até mesmo, "chato". Esse preconceito pode ser reforçado pelas práticas pedagógicas preocupadas somente em transmitir uma série de conceitos como rima, métrica, verso, estrofe, entre outros, e, algumas vezes, em estudar aspectos gramaticais. Esse é um modelo que, ao invés de atrair o aluno para a leitura, o afasta dela, uma vez que ignora os aspectos subjetivos como afetividade, sensibilidade e imaginação criadora que transcendem a simples estrofação e versificação. Ignora, inclusive, o mundo da linguagem que nos constitui e por nós é constituída, aprendida, criada e ressignificada.

Textos literários e imagens fotográficas sempre narram algo. Devemos, por isso, aprender a notar os significados que envolvem, entender como esses foram construídos e encadeados, identificar a perspectiva que oferecem e o efeito que provocam nos nossos olhos de leitores de palavras e imagens.
Embora literatura e fotografia sejam linguagens diferentes e baseiem-se em procedimentos distintos de construção e expressão, ambas são formas de representação, relacionam-se profundamente e permitem ampliar as discussões teóricas e conceituais do letramento literário, ao mesmo tempo em que abrem novas e mais diversificadas possibilidades para o ensino da leitura poética e o trabalho em sala de aula.

Nesse sentido, o presente artigo desenvolve reflexões teóricas, percorre os caminhos da criação literária e fotográfica, apresenta seus diálogos possíveis, propõe estratégias que podem ser incorporadas ao dia a dia escolar. Buscando, assim, oferecer alternativas para o ensino da disciplina de Língua Portuguesa através da construção de um conhecimento plural e interdisciplinar, que contribua na formação de melhores leitores de textos e imagens, oferecendo um novo enfoque para a incorporação de textos literários e recursos visuais para formação do aluno, visando à melhoria do rendimento escolar e ao desenvolvimento da capacidade intelectual dos alunos.

\section{Leitura e letramento literário}

Ler constitui-se em ato de extrema valia para o desenvolvimento cultural e social de qualquer cidadão. 0 incentivo à leitura deveria iniciar no ambiente familiar, entretanto, muitas crianças têm seu primeiro encontro com o livro e com a literatura na escola. Nesse sentido, pode-se afirmar que o professor tem papel fundamental na inclusão da literatura na vida dos alunos, pois é na escola que as crianças terão a oportunidade de dar seus primeiros passos rumo ao mundo da leitura.

A escola tem a função de mostrar ao aluno que a leitura pode ser uma fonte inesgotável de lazer e novos conhecimentos; pode ser vista como emancipação. Candido (1995, p. 240) afirma que:

A literatura também é uma forma de reprodução da cultura e como tal deve ser valorizada em todas as classes sociais, pois tem o poder de ampliar a visão que temos do mundo, ela é uma grande fonte de conhecimento e deveria ser o centro de interesse nas aulas de Língua Portuguesa para concretizar a sua finalidade principal que é que os alunos leiam e escrevam bem, além de despertar o gosto e interesse pela leitura. 
Segundo o autor, para formar leitores é indispensável a participação da família desde os primeiros anos, mas a escola e a sociedade também participam dessa construção. Todos precisam estar cientes da importância da leitura na formação cultural do cidadão.

Partindo dessa fala de Candido (1995), presume-se que a escola assume a responsabilidade de iniciar a criança no processo de alfabetização e de, paulatinamente, aperfeiçoar sua leitura, de modo a garantir-lhe o domínio de uma prática, cuja finalidade não se esgota em si mesma.

Além dos benefícios à aprendizagem, a inserção ao mundo mágico da leitura proporciona momentos de lazer, entretenimento e acesso às experiências e situações vividas pelas personagens. De acordo com essa premissa, vale ressaltar que um dos meios de propiciar ao aluno a oportunidade de desenvolver o gosto e o hábito de leitura é apresentar-lhes textos literários por meio da linguagem verbal e da não verbal, isto é, das palavras, dos gestos e das imagens.

A palavra é a matéria-prima da literatura. Segundo Cosson (2012, p. 16) "nosso corpo linguagem é feito das palavras com que o exercitamos, quanto mais eu uso a língua, maior é o meu corpo linguagem e, por extensão, maior é o meu mundo." Para o autor, no exercício do corpo linguagem, é que o corpo palavra e o corpo escrita se encontram no mais perfeito exercício.

Na leitura e na escrita do texto literário encontramos o senso de nós mesmos e da comunidade a que pertencemos. A literatura nos diz o que somos e nos incentiva a desejar e a expressar o mundo por nós mesmos. E isso se dá porque a literatura é uma experiência a ser realizada. É mais que um conhecimento a ser reelaborado, ela é a incorporação do outro em mim sem renúncia da minha própria identidade. No exercício da literatura, podemos ser outros, podemos viver como os outros podemos romper os limites do tempo e do espaço de nossa experiência e, ainda assim, sermos nós mesmos. É por isso que interiorizamos com mais intensidade as verdades dadas pela poesia e pela ficção (COSSON, 2012, p. 17).

Assim, a literatura proporciona a corporização da palavra por meio da arte. Proporciona o prazer estético, estimula o diálogo e novas experiências, melhora seu processo cognitivo e, principalmente, traz novas concepções de mundo. Segundo Candido:
A literatura é essencialmente uma reorganização do mundo em termos de arte; a tarefa do escritor de ficção é construir um sistema arbitrário de objetos, atos, ocorrências, sentimentos, representados ficcionalmente conforme um princípio de organização adequado à situação literária dada, que mantém a estrutura da obra (2010, p. 187).

Como afirma o autor, a reorganização que está presente na arte é capaz de possibilitar ao leitor a experiência humana que mudará sua visão de mundo. Humaniza-se a partir do contato com a produção artística. Humanização essa entendida como:

[...] processo que confirma no homem aqueles traços que reputamos essenciais, como o exercício da reflexão, a aquisição do saber, a boa disposição para com o próximo, o afinamento das emoções, a capacidade de penetrar nos problemas da vida, o senso da beleza, a percepção da complexidade do mundo e dos seres, o cultivo do humor (CANDIDO, 2011, p. 182).

Portanto, a literatura tem potencial para humanizar, pois traz além dos valores sociais preconizados, bem como a contradição desses, o que permite ao leitor ultrapassá-los, possibilitando a vivência dialética dos problemas elevando seu espírito e mente, e organizando sua visão de mundo. Assim, a literatura pode ser compreendida como a arte da palavra humanizadora.

Candido também faz referência às funções conferidas à literatura: função psicológica e função formadora. Afirma que a psicológica está relacionada à necessidade que o homem tem da ficção, da fantasia, independente da classe social ou cultural. $\mathrm{E}$ a formadora, que se refere à leitura como caráter formativo, educativo, tanto quanto a família e a escola. $O$ autor acredita ser a literatura de fundamental importância na vida do homem, considerando um direito básico de todo cidadão.

A literatura é um importante e indispensável instrumento para educar, e a leitura é a base e o ponto de partida e chegada do letramento literário tão importante na formação dos estudantes.

De acordo com Magda Soares (2004), a palavra letramento, assim como o seu conceito, é algo recente no Brasil. Foi introduzido na linguagem da educação e das ciências linguísticas há pouco mais de duas décadas. Seu surgimento se deu pela necessidade de configurar e nomear comportamentos e práticas sociais na área da leitura e da escrita que ultrapassassem o domínio do sistema alfabético e 
ortográfico. Esses comportamentos e práticas sociais de leitura e de escrita foram adquirindo visibilidade e importância à medida que a vida social e as atividades profissionais tornaram-se cada vez mais centradas e dependentes da língua escrita, revelando a insuficiência de apenas alfabetizar no sentido tradicional.

O letramento não é unicamente pessoal, mas é, sobretudo, uma prática social: "letramento é o que as pessoas fazem com as habilidades de leitura e escrita, em um contexto específico, e como essas habilidades se relacionam com as necessidades, valores e práticas sociais" (SOARES, 2004, p. 72).

É importante esclarecer que o conceito de letramento abarca dois fenômenos diferentes, embora complementares: a leitura e a escrita. Esses dois, por sua vez, são constituídos por um "conjunto de habilidades, comportamentos, conhecimentos que compõem um longo e complexo continuum" (SOARES, 2004, p. 48-49). Um indivíduo pode ser capaz de ler um bilhete e não ser capaz de ler uma notícia, pode ser capaz de escrever o nome e não ser capaz de escrever um bilhete, e assim por diante: "há diferentes tipos e níveis de letramento, dependendo das necessidades, das demandas do indivíduo e de seu meio, do contexto social e cultural" (SOARES, 2004, p. 48- 49).

Como letramento, Kleiman (1995) destaca uma prática discursiva de determinado grupo social que está relacionada ao papel da escrita para tornar significativa essa interação oral, mas que não envolve, necessariamente, as atividades específicas de ler ou de escrever. Assim, o letramento é um conjunto de práticas sociais que perpassam a escrita. Para Kleiman:

0 fenômeno do letramento, então, extrapola o mundo da escrita tal qual ele é concebido pelas instituições que se encarregam de introduzir formalmente os sujeitos no mundo da escrita. Pode-se afirmar que a escola, a mais importante das agências de letramento, preocupa-se não com o letramento, prática social, mas com apenas um tipo de letramento, a alfabetização, o processo de aquisição de códigos (alfabético, numérico), processo geralmente concebido em termos de uma competência individual necessária para o sucesso e promoção na escola. Já outras agências de letramento, como a família, a igreja, a rua como lugar de trabalho, mostram orientações de letramento muito diferentes (KLEIMAN, 1995, p. 20).
No âmbito da sala de aula, os gêneros literários têm exercido, muitas vezes, o papel de pretexto para ensinar aspectos gramaticais da língua (COSSON, 2006). Outro engano reside no fato de associar a leitura literária ao prazer. Ninguém nasce gostando ou não de ler. É preciso despertar nos sujeitos a habilidade de leitura, uns irão gostar; outros entender que é necessário, e assim, o farão.

Tornar o ensino/aprendizagem de literatura em uma prática significativa deve ser prioridade em nossas escolas, mas, para isso, é preciso repensar o conceito de literatura, seu valor e função social. Indo ao encontro da necessidade de melhorar o ensino de literatura em nossas escolas, estudos apontam para o letramento literário, um tipo de letramento em que a literatura é vista de maneira mais ampla.

Em uma de suas obras, Cosson (2006) apresenta estratégias que visam desenvolver o letramento literário na escola. Tendo a leitura como objetivo principal desse tipo de letramento, o teórico destaca que a leitura do aluno deve ser discutida, questionada e analisada. Cosson defende a construção de uma comunidade de leitores como objetivo maior do letramento literário na escola.

Soares (2006) observa, ainda, que as atividades propostas na escola não visam à textualidade ou literariedade, transformando o texto literário em um mero texto informativo, que tem como pretexto exercícios de metalinguagem. A autora ressalta que a escolarização é inevitável, porque é da essência da escola a didatização de conhecimentos e práticas culturais, mas que é possível fazer uma escolarização adequada:

Distinguimos entre uma escolarização adequada e uma escolarização inadequada da literatura: adequada seria aquela escolarização que conduzisse eficazmente às práticas de leitura literária que ocorrem no contexto social e às atitudes e valores próprios do ideal do leitor que se quer formar; inadequada é aquela escolarização que deturpa, falsifica distorce a literatura, afastando, e não aproximando, o aluno das práticas de leitura literária, desenvolvendo nele resistência ou aversão ao livro e ao ler (SOARES, 2006, p. 47).

A literatura precisa de um adequado processo de escolarização, mas não de modo que seja descaracterizada e negada sua função social, pois a correta escolarização da literatura contribui para a formação dos estudantes em uma perspectiva do letramento literário. 
É preciso problematizar e rever as práticas de leitura no contexto escolar. Ler fragmentos de textos em livros didáticos, fazer fichas de leitura, provas e exercícios gramaticais baseados em textos literários, não tem utilidade para os alunos, pois não objetivam trabalhar a leitura literária, e muito menos o letramento. São tarefas enfadonhas que nada acrescentam à vida do estudante.

O professor é o principal responsável pela mediação entre o leitor e o livro no contexto escolar. Um dos papéis fundamentais do professor é o de apresentar obras literárias aos alunos, selecionar as obras que devem ser lidas e trabalhadas visando ao letramento literário dos estudantes. Para a formação do leitor aprendiz, é indispensável a presença de um professor mediador. Assim, se faz necessário que a escola privilegie a formação literária dos alunos através da leitura e de estratégias de ensino, e o professor deve assumir a posição de mediador do conhecimento, que conduz o processo.

\section{Imagem fotográfica}

Diante do desafio de trabalhar com o poema em sala de aula, surge a possibilidade de aliar a fotografia com a poesia, uma vez que nossos estudantes sentem-se atraídos pelas novas tecnologias, principalmente pelo celular e sabemos como estão envolvidos com o ato de fotografar e filmar tudo o que acontece a sua volta. Sendo assim, cabe o estudo e a discussão das interrelações entre literatura e fotografia, as potencialidades poéticas da fotografia para alcançar o letramento literário dos estudantes.

A fotografia possui a tecnologia necessária para colocar em prática um desejo que sempre esteve na mente das pessoas: o de fixar momentos da existência. Para o escritor Mario Quintana (apud MONTEIRO, 2015), "o fotógrafo tem a mesma função do poeta: eternizar o momento que passa". Capturar ou descrever vivências parece ser um dos maiores desafios dentro da comunicação humana. E, no mundo da cultura e das artes, essa intenção pode ser observada por meio da literatura e da fotografia.

Experiências, como as de Florence (1830) e as de muitos outros ao redor do mundo, demonstram o grande número de pessoas empenhadas no aperfeiçoamento do que viria a ser a fotografia. Uma forma de representação técnica e simples que era aguardada pela sociedade industrializada do século
XIX, a qual já pressentia que possuía a tecnologia necessária para colocar em prática um sonho antigo da humanidade: o de fixar momentos da existência.

A revolução causada pela invenção da fotografia nas artes da representação, traz a ideia de que o real e o instante podiam ser apreendidos pela primeira vez, em uma forma de representação que se aproximava bastante de uma percepção. Sob esse ponto de vista, "a fotografia restitui sobre uma superfície contínua o traço ou o rastro de tudo o que o olhar apanha em um piscar de olhos" (KRAUSS, 1990, p. 119).

Com a fotografia ocorreu uma sensação de vitória contra um dos fenômenos mais misteriosos da vida: o tempo. Decorre daí, talvez, um dos principais motivos do fascínio exercido pela fotografia que, em pouco tempo, torna-se uma febre mundial.

Sontag esclarece que "assim como a industrialização propiciou os usos sociais para as atividades do fotógrafo, a reação contra esses usos reforçou a consciência da fotografia como arte" (2004, p. 26).

No mundo das artes, no entanto, a fotografia é recebida com desconfiança por alguns intelectuais que a consideravam uma concorrente desleal da pintura. Mas a polêmica que se desenvolveu, ao longo do século XIX, entre pintores e fotógrafos sobre o valor artístico de suas respectivas obras foi, segundo Walter Benjamin (1975, p. 20), uma discussão em torno de um falso problema: "Gastaram-se vãs sutilezas a fim de se decidir se a fotografia era ou não arte, porém não se indagou antes se essa própria invenção não transformaria o caráter geral da arte". E foi exatamente uma espécie de revolução no mundo das artes o que fez a fotografia, conforme atesta Benjamin (1975, p. 13):

Com o advento do século XX, as técnicas de reprodução atingiram tal nível que, em decorrência, ficaram em condições não apenas de se dedicar a todas as obras de arte do passado e de modificar de modo bem profundo os seus meios de influência, mas de elas próprias se imporem, como formas originais de arte.

Exatamente no momento em que pararam de discutir se a fotografia era ou não uma arte, ela passou a ser assim aclamada pelo público em geral e ingressou, à força, nos museus. Sua naturalização como arte é a vitória conclusiva da campanha de um século travada pelo gosto modernista em favor de uma definição de arte sem fronteiras, uma vez que a fotografia oferecia um campo muito mais conveniente do que a pintura para esse esforço. Pois, a 
diferença entre amador e profissional, primitivo e sofisticado, não é só mais difícil de traçar do que na pintura, mas tem pouco sentido. A fotografia ingênua, despretensiosa, não difere, no tipo, da fotografia praticada pelos profissionais mais talentosos: há fotos tiradas por amadores anônimos tão interessantes, tão complexas, tão representativas quanto uma foto de um profissional. Isso podemos comprovar durante a aplicação de nossa intervenção pedagógica através das fotos que os estudantes tiraram usando seus aparelhos celulares.

A princípio, a fotografia foi vista como uma atividade arrogante, que parecia rebaixar uma arte já estabelecida: a pintura. Para Baudelaire (1993 apud SONTAG, 2004), a fotografia era "inimiga mortal" da pintura; mas, no fim, elaborou-se uma trégua, onde a fotografia era tida como libertadora da pintura, da cansativa tarefa da representação fiel, podendo assim, partir para busca de uma tarefa mais elevada: a abstração, selando um pacto que autorizou ambas a perseguirem tarefas distintas.

0 fascínio diante de uma fotografia surge, dessa sua capacidade de reproduzir, de forma bem convincente, o instante. Atualmente esse fascínio é ainda maior, pois não há mais a necessidade de se carregar uma máquina fotográfica para conseguir eternizar momentos, basta ter à mão os modernos aparelhos celulares que são capazes de fotografar, editar e publicar uma foto em questão de segundos.

0 texto "Literatura e fotografia: o anseio pela apreensão do instante", dos autores Pedro Carlos Louzada Fonseca e Fábio D’Abadia de Sousa (2008), propõe que a literatura, especialmente no campo poético, e a imagem fotográfica possuem a função de ampararem e complementarem uma à outra na hora de contar uma história, e, consequentemente, de registrar um momento.

Se a ilusão da captura é feita por um clique, que pode ter êxito ou não na tentativa do registro, o resultado pode ser considerado algo unânime, extraordinário e único. Ao relacionar a imagem com a palavra, utilizamos vários recursos para expressar a complexidade dos sentimentos envolvidos em um dado momento.

Se, na literatura, as palavras convertem-se em imagens, na fotografia são as imagens que geram as palavras. Cada um mirará, de maneira singular, a realidade, de acordo com as características de cada indivíduo e objeto retratado.

Sontag (2004, p. 112), ao estabelecer uma relação de pertinência entre literatura e fotografia, considera que o ethos, ou conjunto de valores, da fotografia está mais próximo da poesia moderna do que o da pintura. Sobre essa correspondência comenta a autora:
Enquanto a pintura se tornou cada vez mais conceitual, a poesia (desde Apollinaire, Eliot, Pound e Willian Carlos Williams) definiu-se cada vez mais como uma atividade ligada ao visual. ("Não há verdade senão nas coisas", como declarou Williams). O compromisso da poesia com o concreto e com a autonomia da linguagem do poema corresponde ao compromisso da fotografia com a visão pura. Ambos supõem descontinuidade, formas desarticuladas e unidade compensatória: arrancar as coisas de seu contexto (vê-las de um modo renovado), associar as coisas de modo elíptico, de acordo com as imperiosas, mas não raras arbitrárias exigências da subjetividade.

Essa capacidade que tanto a poesia quanto a fotografia possuem de permitir uma visão renovada acerca das coisas, talvez, tenha o seu nascimento e a sua justificativa no fato de as duas modalidades artísticas buscarem, na tentativa de apreensão dos fragmentos de realidade circundante, o motivo da sua existência.

Literatura e fotografia, duas formas de arte aparentemente tão diferentes, na verdade, são semelhantes em sua essência e manifestação. Na contemporaneidade, muitos artistas substituíram a paleta de tintas por uma câmera fotográfica e, por meio dela, buscam captar seu olhar poético do mundo: "Fotos, que em si mesmas nada podem explicar, são convites inesgotáveis à dedução, à especulação e à fantasia" (SONTAG, 2004, p. 76).

A poesia traz a possibilidade de imaginar, de visualizar e a fotografia traz a poesia em suas imagens. Interligar a poesia e a fotografia possibilita que imagens sejam criadas a partir da leitura e interpretação das palavras, o que possivelmente proporcionará a formação imagética da escrita e do pensar por imagens em uma perfeita catarse.

\section{Barthes: poesia e fotografia}

Nos quase trinta anos em que esteve em atividade como escritor, Roland Barthes, escreveu e publicou obras dos mais variados temas. Durante essas quase três décadas de trabalho, a fotografia aparece constantemente em suas obras. Um dos eventos representativos e antropológicos mais importantes da revolução industrial não passa despercebido por ele. 
O fato de a fotografia, diferentemente dos meios representativos, até então conhecidos, relacionar-se com seu objeto de forma direta, sem a aparente mediação de um código, espanta Barthes. Esse entendimento de oposição entre as artes tradicionais, como a pintura, tidas como lugar da imaginação criadora e a fotografia, como espaço limitado de transformação, moldou grande parte do pensamento sobre a fotografia nos últimos anos. "Diríamos que a Fotografia é inclassificável. [...] 0 que a fotografia reproduz ao infinito só ocorreu uma vez: ela repete mecanicamente o que nunca mais poderá repetir-se existencialmente" (BARTHES, 2015, p.14).

Com o livro A Câmara Clara (1980), Barthes parece buscar outras possibilidades inerentes à fotografia, como se, além das camadas frias do significante e do significado, a fotografia ocultasse outros sentidos, que envolvem de certa forma a imaginação e os laços afetivos.

Para dar conta do que seria o fenômeno fotográfico, Barthes parte do espanto que ela lhe causa, da questão da presença necessária do objeto diante da câmera que o capta, da relação entre o signo e o referente. Não se coloca como um observador isento, mas como um ser afetivo, diante de imagens que lhe remetem a afetos.

Barthes não escreve uma teoria da imagem fotográfica, como muitos aguardavam, ele prefere falar da experiência de estar diante de algumas imagens, optando pelo discurso estético e não técnico. Propõe a liberdade do olhar como quem busca o grau zero da imagem, o branco da linguagem. "No fundo, a Fotografia é subversiva, não quando aterroriza, perturba ou mesmo estigmatiza, mas quando é pensativa" (BARTHES, 2015, p. 38). Deixa claro que em uma fotografia sempre coexistem dois observadores: o fotógrafo (aquele que tira a foto) e o leitor da imagem depois de processada (o espectador), que é convidado a participar das múltiplas interpretações possíveis sem exigir uma interpretação finalizante.

A fotografia nos prepara, de certa forma, para encarar o aspecto da impotência do tempo. Podemos dizer que a simpatia de Barthes pela fotografia se dá pelo fato de a considerar como catalisador da memória. Nada na fotografia, segundo ele, se aproxima de uma busca por um tempo perdido. Quem observa uma foto não revive aquele momento, em uma espécie de atuação ativa diante do passado, mas, de forma mais chocante, esse passado retorna, torna-se presente, sem qualquer influência do espectador. Barthes coloca o espectador como um ser impotente diante desse passado que, em estado presente, contrai o tempo e se lança sobre o olhar do observador. A fotografia, para ele, está associada, necessariamente, à morte, pela aptidão natural e real de congelar o tempo. "Na fotografia, a imobilização do Tempo só ocorre de um modo excessivo, monstruoso: o Tempo é obstruído" (2015, p. 78).

Na compreensão barthesiana (2005, p. 47-48), "Haicai = forma exemplar de anotação do presente $=$ ato mínimo de enunciação, forma ultrabreve, átomo de frase que anota (marca, cinge, glorifica: dota de uma fama) um elemento tênue da vida real, presente, concomitante".

É no início dos anos 1970 que Roland Barthes, pela primeira vez, refere-se à possibilidade comparativa entre fotografia e haikai. Na obra $O$ Império dos Signos, afirma: “[...] o flash do haicai não ilumina, não revela nada; é como uma fotografia que tirássemos com muito cuidado (à japonesa), mas tendo esquecido de carregar o aparelho com a película" (BARTHES, 2007, p. 112).

Seu interesse pela cultura oriental recai sobre o haikai, muito associado por Barthes à imagem fotográfica. Essa forma poética breve, capaz de aprisionar o instante chama-lhe a atenção.

[...] o que a ação química desenvolve é o indesenvolvível, uma essência (de ferida), o que não pode transformar-se, mas apenas repetir-se sob as espécies da insistência (do olhar insistente). Isso aproxima a Fotografia (certas fotografias) do Haiku. Pois a notação de um Haiku também é indesenvolvível: tudo está dado, sem provocar a vontade ou mesmo a possibilidade de uma expansão retórica (BARTHES, 2015, p. 46).

Será no livro 0 império dos signos que Barthes irá tratar dessa forma poética pela primeira vez. 0 deslumbramento com essa forma enxuta de poesia vai fazê-lo repensar seus pensamentos e teorias sobre a arte poética. Em, A preparação do romance, podemos visualizar a mudança radical de opinião: "compreende-se, então, talvez isso: Poesia = prática da sutileza num mundo bárbaro. Daí a necessidade de lutar hoje pela Poesia: a Poesia deveria fazer parte dos 'Direitos do Homem'; ela não é 'decadente', ela é subversiva e vital" (BARTHES, 2005, p. 95).

Essa mudança se deve ao fato da busca pela capacidade de uma escrita neutra, manifestada agora pela poesia, de assegurar ao sujeito processos de escape à qualquer tipo de coação perante as regras da língua, permitindo ao sujeito uma liberdade, o lugar da fantasia.

Barthes parece encontrar na poesia a vitalidade final de um texto desimpedido de ideias prontas. Essa capacidade de captar o objeto, o instante, praticamente 
no momento em que ocorre, irá atrai-lo na defesa do haikai como uma forma neutra de manifestação literária e permitirá sugerir a aproximação de tal forma poética com a fotografia. Aliás, entender a relação dele com o haikai passa pelo entendimento da atração de Barthes pelo fragmento, jamais escreveu para estar certo de algo, mas para causar impressão e tanto a fotografia quanto o haikai lhe permitiram essa liberdade.

Sob forma de pensamento-frase, o germe do fragmento nos vem em qualquer lugar: no café, no trem, falando com um amigo (surge naturalmente daquilo que ele diz ou daquilo que digo); a gente tira então o caderninho de apontamentos, não para anotar um "pensamento", mas algo como um cunho, o que se chamaria outrora um "verso" (BARTHES, 2003, p. 109).

Literalmente, reproduz com palavras a ação de um fotógrafo, só que utiliza o caderninho de anotações ao invés da câmera fotográfica. O haikai, bem como a fotografia, levam Barthes, diante de ambos, dizer, como num olhar sem objetivo: "Nos dois casos, poderíamos falar de uma imobilidade viva" (2015, p. 46).

O que há segundo ele, no haikai e na fotografia, é um encontro (não um reencontro) com o tempo, em uma captura do instante, do estalo, do que ele chama de tilt, aquilo que nos toca sem sabermos por que, uma surpresa. Vê, em ambos, a mesma qualidade intrínseca de apanhar o instante e desequilibrar a linguagem ao ponto de torná-la neutra. Para ele, nos levam ao prazer instantâneo, uma abertura para o desejo, "um fantasma de discurso" (2003, p. 109).

Para Barthes, a fotografia é a forma de arte que permite conceber o haikai, por ultrapassar os limites do simples diálogo entre texto e imagem, tão comuns hoje principalmente nos veículos midiáticos. É por seu vigor imagético que o haikai produz o mesmo efeito do momento que a fotografia traz. Assim, o fotógrafo e o poeta aproximam-se pela capacidade de aprisionar momentos. E é, esse aceno do real, contido na fotografia, assim como no haikai, que interessa a Barthes.

\section{0 haikai como proposta de ensino da poesia nas aulas de língua portuguesa}

O ensino da poesia em sala de aula contribui de forma singular para a formação do leitor literário, visto que é um gênero que parte da linguagem verbal e que, por intermédio de uma atitude criativa parte do usual para recursos formais e semânticos. Assim, na poesia, a linguagem verbal, o ritmo, as imagens e o sentido apresentam um mundo que o leitor precisa compreender para poder vivenciar e reelaborar seu pensamento, como claramente nos aponta Azevedo (2001 apud SOUZA, 2004, p. 44):

A literatura, o discurso poético e ficcional, quando respeitadas suas características, entre as quais, ressalto mais uma vez, incluo a possibilidade de poder abordar o contraditório, permite a identificação emocional entre a pessoa que lê e o texto e, assim, pode representar, dentro ou fora da escola, um precioso espaço para que certas especulações vitais - feitas pelo leitor, seja consigo mesmo, seja com outras pessoas - possam florescer

Por que nossos alunos em sala de aula costumam afirmar que não gostam de ler poesia? Será que não gostam ou não a têm vivenciado de forma que se sintam seduzidos e encantados? Muitas vezes a forma como é trabalhado o gênero poema em sala de aula acaba por distanciar os alunos da arte poética.

Conforme afirma Sorrenti (2009, p. 17), "destina-se, geralmente, à escola a tarefa de criar no aluno o gosto pela poesia. No entanto, ela pode ser, por vezes, responsável pelo desgosto pela poesia".

Nos últimos anos, têm-se manifestado preocupações diversas no que diz respeito à formação de leitores. Compreendendo sua atuação como instituição formadora, a escola volta seus olhos ao campo da literatura, esperando encontrar algumas soluções para as graves lacunas do ensino, pois, mesmo polemizada por sua não praticidade, a literatura termina ocupando necessariamente o centro das atuais discussões sobre educação quando se refere à formação do leitor e sem saber por que, e, para que estudar literatura, o estudante fatalmente desanima frente ao texto. 
A poesia pode estabelecer uma ponte entre a criança e o mundo. [...] durante muito tempo, acreditou-se que, para aproximar a criança da poesia, bastava apresentar-lhe textos de qualidade. Sabe-se hoje que é preciso somar outros elementos a essa aproximação, entre os quais o entusiasmo do professor ou mediador. Um mediador sensível ao texto poético tornar-se-á o grande iluminador do encontro texto-leitor. Ele é peça importante na formação do gosto pela poesia (SORRENTI, 2009, p. 19).

Logo, bons textos pré-selecionados são importantes, mas não suficientes. 0 professor deve criar em sala de aula uma atmosfera poética de liberdade e criatividade para que a expressão flua sem bloqueios, lembrando que a interação texto poético/leitor requer carinho e competência.

Conforme Candido (2011, p. 182), "as produções literárias, de todos os tipos e todos os níveis, satisfazem necessidades básicas do ser humano, sobretudo através dessa incorporação, que enriquece a nossa percepção e a nossa visão do mundo".

0 dia a dia escolar é fomentado por uma contra formação que nele se insere por meio dos avanços tecnológicos e tal crescimento exige mudanças no que se refere à prática de ensinar e aprender. Deste modo, cabe ao educador uma reflexão acerca dos novos rumos que a educação os coloca, em sala de aula, principalmente no que se refere à literatura como força humanizadora. Candido (2011, p. 182) afirma que "a literatura desenvolve em nós a quota de humanidade na medida em que nos torna mais compreensivos e abertos para a natureza, a sociedade, o semelhante".

Rildo Cosson, no livro Letramento literário: teoria e prática, defende que o processo de letramento literário é diferente da leitura literária por fruição, aliás, uma depende da outra. Segundo ele,

[...] devemos compreender que o letramento literário é uma prática social e, como tal, responsabilidade da escola. A questão a ser enfrentada não é se a escola deve ou não escolarizar a literatura, como bem nos alerta Magda Soares, mas sim como fazer essa escolarização sem descaracterizá-la, sem transformá-la em um simulacro de si mesma que mais nega do que confirma seu poder de humanização (COSSON, 2014, p. 23).

O autor completa ainda dizendo que, dessa forma, no letramento literário não podemos simplesmente exigir que o aluno leia a obra e ao final faça uma prova ou ficha, pois a leitura é construída a partir dos mecanismos que a escola desenvolve para a proficiência da leitura literária. Em seu texto, Cosson apresenta um interesse claro pelo ensino de literatura na escola básica, pois esse letramento literário busca formar "uma comunidade que se constrói na sala de aula, mas que vai além da escola, pois fornece a cada aluno e ao conjunto deles uma maneira de ver e viver o mundo" (2014, p. 12). A escola tem papel singular nesse momento, visto ser ela talvez a principal responsável pela formação e consolidação de alunos leitores, para que sejam críticos e atuantes de fato.

A prosa literária ocupou espaços que antes eram destinados à poesia, e isso se deve à forma como o poema é trabalhado nas escolas, não de uma forma que faça com que os alunos se encantem e tenham gosto pela leitura, mas, sem o devido valor que a poesia merece. 0 importante é que o professor estimule os seus alunos a escutar essa linguagem poética, despertando assim seus ouvidos para os versos. Por isso, a importância da promoção do letramento literário no processo de escolarização da literatura.

Conscientes de que a poesia ainda é um gênero literário, distante da sala de aula, é preciso descobrir formas de familiarizá-la e torná-la próxima das crianças, adolescentes e jovens.

A forma de se ensinar a leitura literária no âmbito do ensino fundamental e médio, principalmente no tocante à literatura, sempre foi vista como um sistema de obras e autores, história literária ou conjunto de textos consagrados, mas sem contexto nenhum com a realidade que circundam os alunos. Persiste uma didática de transmissão de informações fragmentárias acerca da literatura, em uma concepção de ensino na qual se tem separadamente língua, literatura e redação. Para Todorov:

O conhecimento da literatura não é um fim em si, mas uma das vias régias que conduzem à realização pessoal de cada um. 0 caminho tomado atualmente pelo ensino literário, que dá as costas a esse horizonte [...] arrisca-se a nos conduzir a um impasse - sem falar que dificilmente poderá ter como consequência o amor pela literatura (2009, p. 33).

A aprendizagem da interpretação da poesia compreende o desenvolvimento em coordenar conhecimentos dos vários sentidos que um texto poético proporciona. Evidente que a personalidade do professor e, particularmente, seus hábitos de leitura são importantíssimos para desenvolver os interesses e hábitos de leitura 
nos alunos. De tal modo, espera-se que os professores percebam a importância do emprego da poesia em sala de aula para a formação leitora da criança e do adolescente, pois como afirma Candido (2011, p. 193): "uma sociedade justa pressupõe o respeito dos direitos humanos, e a fruição da arte e da literatura em todas as modalidades e em todos os níveis é um direito inalienável”.

Para reforçar o haikai como objeto de estudo em sala de aula, abordaremos a colaboração de alguns especialistas no assunto, que deram suas opiniões a respeito do haikai como objeto de estudo em sala de aula, sua metodologia e didática de ensino, ou seja, o porquê ensinar e como ensinar.

Para Clement (2007), ensinar o haikai para crianças ou jovens é uma ideia inovadora que vale a pena introduzir como um tema cultural adicional, mas que exige um grande esforço tanto da parte de quem ensina como de quem aprende. 0 primeiro desafio, diz ela, é explicar por que os alunos deveriam se interessar por um conceito de poesia que pertence a uma cultura com a qual temos pouco envolvimento, como a cultura japonesa. Vencido esse obstáculo, ensinar o haikai pode ter várias finalidades tanto dentro como fora da sala de aula.

Clement (2007) acrescenta ainda que o haikai já é importante só pelo fato de permitir uma interação do aluno com a natureza, nessa época de aquecimento global. Ao manter o foco em uma cena da paisagem, o aluno aprende a observá-la, admirá-la, amá-la e explorá-la para dela tirar a essência e um momento de reflexão. Além disso, permite ao aluno usar todos os seus sentidos de forma mais apurada e o estimula a compartilhar suas experiências e percepções com as pessoas ao seu redor. 0 professor deve informar que um haikai é todo feito de imagens, que são essas imagens que criam as emoções que eles sentiram durante a leitura do poema.

0 autor afirma também que é importante que o professor seja gentil e aceite as tentativas do haikai dos estudantes e os encoraje a tentar novos caminhos até que eles se sintam confortáveis com o método. 0 professor deve evitar o excesso de entusiasmo em querer promover de imediato algum tipo de concurso ou comparar resultados. Promover meios de publicação, como antologias, cartões, camisetas, exposições e assim por diante podem ser usados para estimular o interesse do aluno pelo haikai. Além da lousa ou quadro negro, podem ser usados projetor, slides, fotos etc. Tudo depende da imaginação do professor, conclui Clement (2007).

Diz ainda que escrever um poema não é mais fácil que escrever um haikai. Cada um possui seu conjunto de regras. A prática do haikai está se espalhando cada vez mais rapidamente. Aparece em plena expansão na internet, no rádio e está começando a ganhar espaço não somente nas escolas, mas também nas universidades.

Na opinião de Marins (2007) sobre o assunto, diz o haicaísta que o haikai contém em sua forma, ou melhor, em seu formulário tudo que precisamos para aprender poesia. Acrescenta que fazer um poema nos moldes de um haikai implica em um aprendizado que envolve os elementos básicos de um poeta: vivência, percepção, observação treinada, conhecimento da sintaxe poética (métrica, ritmo, algumas figuras de linguagem etc.), o apuro da linguagem e, ao mesmo tempo, manter também a simplicidade, a pureza do momento do haikai captado, ou seja, sem intelectualizar, sem tornar mental ou sentimental demais.

Na Revista de haikai Caqui (2002), no ensaio "Ao professor", há algumas perguntas feitas a William Higginson, autor de The Haiku Handbook sobre o porquê ensinar o haikai às crianças. 0 escritor responde que o haikai nasce da experiência do poeta, através da observação da natureza no dia a dia e acrescenta que o haikai é mais fácil de ser entendido, ficando livre de interpretações esotéricas, pois a natureza do haikai é infantil, por ver as coisas como elas são. Higginson acrescenta ainda que as crianças, quando estimuladas pelos orientadores, encontram seu próprio entendimento dos haikais, da mesma forma que aprendem a encontrar seu próprio entendimento de mundo, implicando mais em uma observação atenta do que em um conhecimento esotérico.

Teruko (2002) ${ }^{2}$ acrescenta que para alcançar a concisão no poema, é preciso insistir na simplicidade, na escolha de um tema que seja importante para a criança e, não se prender à métrica, porém sugerir uma aproximação do esquema 5-7-5.

Quanto a ensinar a teoria e a história do haikai, Oda $(2002)^{3}$ diz que as crianças não suportam explicações teóricas. Deve haver objetividade por parte do professor a partir da prática, deve haver também direcionamento para experiências objetivas e sensações físicas.

0 professor enquanto mediador do desenvolvimento dos seus alunos é o profissional responsável por superar as dificuldades encontradas no dia a dia e burlá-las por meio de didáticas atrativas. Diante dessas reflexões, é importante reafirmar que trabalhar com poesia é um dos recursos mais encantadores no processo educacional, que visa ao crescimento estético, crítico e literário

Entrevista à Revista Caqui.

Entrevista à Revista Caqui. 
e inventivo das partes envolvidas e o uso da fotografia com certeza é uma ferramenta facilitadora desse letramento literário.

\section{Sugestão de encaminhamento pedagógico}

Com base nos estudos sobre a fotografia enquanto linguagem, fica claro que a imagem, por si só, apresenta diversas possibilidades de ampliação do olhar para a arte.

Porém, mesmo sabendo que sozinha a imagem sustenta essa função, ainda existem fatores que tornam possível ampliar essas experiências entre olhar e imagem.

Refletindo então sobre a relação entre imagem e texto, sobre a escrita poética como fator integrante da imagem para um diálogo com olhar. Tratando não do texto como fator de influência para a compreensão da imagem, mas sim de um possível diálogo entre ambos. Veneroso (2006, p. 49) estabelece relações entre imagem e texto, a fim de quebrar barreiras e estreitar laços entre as diferentes linguagens, e vem por afirmar que a relação entre escrita e imagem "não se dá como uma relação de mera influência, mas de diálogo".

De acordo com esse pensamento, propomos a ideia de trabalhar com educandos dos anos finais do ensino fundamental, fugindo da ideia da escrita como legenda para as fotografias, mas, como objeto de poética, juntamente com as imagens. Dessa maneira os alunos utilizando os aparelhos celulares sairiam para fotografar paisagens do seu entorno e criariam pequenos textos poéticos partindo da sensibilidade para as diferentes imagens construindo haikais para as imagens que lhe afetassem o olhar. Isso com a intenção de criar um diálogo entre as diferentes linguagens: a fotográfica e a escrita poética, e com isso vir a estabelecer uma ampliação de significados à produção artística e possibilidades de reflexão e apreciação estética. Em posse desse material, e para apresentar as imagens fotográficas juntamente com os haikais, propomos como produção artística uma exposição e o livro da turma, com cunho fotográfico, onde o ponto de partida é o registro poético visual do meio em que os educandos vivem.

As linguagens artísticas nos oferecem diversas formas de provocar nos sujeitos o despertar do olhar e a apreciação estética. A fotografia se mostra capaz de exercer essa função de maneira majestosa. Claro, falando aqui da fotografia enquanto linguagem artística, onde existe uma composição, um pensamento por traz da imagem que revela, que poetiza, que oferece potência de criação. Partindo sempre do olhar poético, dos diferentes olhares que se obtém através da lente da máquina fotográfica, do poder que há na relação entre a imagem fotográfica e o olhar.

Refletindo ainda sobre as relações entre poesia e imagem, a fala de Gonçalves (1994), autor que estabelece alguns diálogos aproximando as linguagens de texto e imagem e traz uma rica reflexão que aponta a relação entre texto e imagem como um sistema de signos: "é nesse sistema de signos que se inclui o observador olhante e o olhado enquanto signo aos olhos do leitor. Num movimento ímpar com a palavra, o texto realiza uma espécie de síntese fenomenal da dança entre palavra e imagem" (GONÇALVES, 1994, p. 218).

Dessa forma compreende-se o texto como um forte aliado à imagem, tratando-se de fatores contribuintes para a formação do olhar. Logo, apresentar textos poéticos relacionados as imagens fotográficas podem vir a estabelecer uma ampliação de significados à produção artística e possibilidades de reflexão e apreciação estética.

De um lado, encontramos a fotografia, linguagem que influenciou e influencia de maneira marcante a contemporaneidade; de outro, a poesia, em certo sentido uma "relíquia" em nossos tempos, mas que continua a inspirar a humanidade desde a Antiguidade. Nessa cartografia fronteiriça a "imagem" se destaca como matriz comum, uma defesa expandida da poiesis como linguagem da criação inaugural.

Parte do trabalho pedagógico que aqui se propõe é alinhavar uma pluralidade de referências e de olhares de modo a ampliar as percepções do leitor em relação às duas formas artísticas. Cujo objetivo é provocar e despertar o olhar das pessoas para um posicionamento diferenciado para a fotografia. Ajudando na formação de leitores visuais, aspecto ainda pouco explorado na sociedade cercada e seduzida por uma avalanche de imagens, mas deficiente em leituras apropriadas neste mundo-imagem.

Sendo a fotografia uma linguagem carregada de significações e que nos possibilita viver experiências estéticas, é a partir dela, da captura pela lente, de momentos únicos, que trabalharemos o letramento literário, de uma forma mais poética e sensível. A fotografia se mostra um rico instrumento de arte, capaz de criar uma atmosfera de experiência estética, a fim de elevar o espectador à condição de observador ativo, como possibilidade de ampliação de acervo imagético dos educandos, (re)visitação à memória e ampliação do olhar, contribuindo para formação de um olhar estético-crítico. 


\section{Considerações finais}

Percebe-se o quanto a poesia é desvalorizada na escola, pois muitos alunos e até mesmo alguns professores não gostam de ler poemas por terem uma visão equivocada sobre eles. Na maioria das vezes, o poema acaba sendo trabalhado, como pretexto para análise gramatical ou questionamentos sobre seu aspecto formal somente.

Dessa forma, é relevante que a escola propicie ao aluno momentos de contato com os textos poéticos baseados em metodologias que visem ao letramento literário. Sentindo e apreciando a poesia, o discente se sensibiliza ante o mundo e usufrui dela como um meio de comunicação, inclusive consigo mesmo.

Ao analisar o trabalho com a literatura nas escolas, faz-se necessário considerar que há um desinteresse da grande maioria dos alunos pela prática da leitura, mais notadamente quando se trata do texto poético. Assim, justificase a importância de pesquisas voltadas para a discussão de estratégias metodológicas que possam contribuir para a reversão dessa realidade, visando à elaboração de propostas que partam da realidade objetiva da comunidade escolar, da valorização da capacidade criadora do grupo e da consideração dos aspectos socioeconômico-culturais que interagem com o espaço escolar.

Ler não é uma tarefa fácil, especialmente quando o alvo é o jovem que, muitas vezes, encontra nos meios de comunicação de massa um atrativo muito maior que a leitura proposta pela escola. Tendo em vista essa problemática, faz-se necessária a ressignificação do trabalho com a poesia, de modo que esse gênero textual possa ser utilizado como recurso cognitivo e comunicativo. Ou seja, fazer ver que a poesia pode ser um lugar de resistência, de fomento de ideias, se vivenciada a partir de um trabalho pedagógico que possibilite recuperar a expressão do aluno.

Portanto, nesse contexto, podemos inserir a fotografia e, a partir dela, abrir as portas para todas as leituras que se apresentam em nosso dia a dia, convidando o leitor a participar e a emitir opiniões, levando-o a sentir as emoções presentes nas diversas imagens, cultivando nos jovens o gosto pela arte e pela descoberta do novo.

Uma das maiores heranças que a educação escolar pode deixar a um aluno é a capacidade de ler o verbal e o não verbal, o gosto pela leitura, pois se ele passar pela escola e aprender pouco, mas for um bom leitor, terá nos livros, revistas, sites da internet e outros materiais um prolongamento da sua formação e poderá desenvolver-se muito além do que a escola esperaria de um aluno ideal.

Além disso, a fotografia e a poesia são elementos importantes a serem utilizados como suporte da formação da personalidade, da estruturação do indivíduo e de seu autoconhecimento. A individualidade afirma-se e reafirma-se na possibilidade de expressar-se por meio da imagem e da poesia. Trabalhar a fotografia e a poesia e, a partir delas, abrir as portas para as várias leituras que se apresentam em nosso dia a dia faz sentido quando a proposta é a de educar para o mundo.

A gama de diferentes emoções que essas linguagens traduzem é o que seduz para o verdadeiro aprendizado. É a sensibilidade do leitor através da imagem e da palavra que, dita na hora certa, ou, trabalhada no momento adequado, pode transformar uma situação. Possuí-las como um recurso é um direito fundamental de todos. 0 sentimento é a matéria-prima fundamental na composição poética e fotográfica, por isso, é um meio de se chegar ao aprendizado através da emoção e da sensibilidade, não um conteúdo a mais em uma longa lista a ser memorizada.

Contudo, é justamente dentro desse contexto que se tornam imprescindíveis trabalhos que mobilizem os sentimentos dos jovens, que canalizem essa energia positiva, humanizando mais o espaço escolar. A arte tem esse poder.

\section{Referências}

ABRAMOVICH, Fanny. Literatura infantil: gostosuras e bobices. São Paulo: Scipione, 1989. ARISTÓTELES. Poética. 2. ed. São Paulo: ArsPoética, 1993.

AVERBUCK, L. M. A poesia e a escola. In: ZILBERMAN, R. (org.). Leitura em crise na escola: as alternativas do professor. 11. ed. Porto Alegre: Mercado Aberto, 1993.

BARTHES, Roland. A Câmara Clara. Rio de Janeiro: Nova Fronteira, 2015.

BARTHES, Roland. A preparação do romance, vol. I. São Paulo: Martins Fontes, 2003. BARTHES, Roland. A preparação do romance. vol. II. São Paulo: Martins Fontes, 2005. BARTHES, Roland. O império dos signos. São Paulo: Editora WMF Martins Fontes, 2007. 
BENJAMIN, Walter. A obra de arte na época de suas técnicas de reprodução. In: ARANTES, Otília B. Fiori (org.). Textos escolhidos. São Paulo: Abril Cultural, 1975.

BERALDO, Aldo. Trabalhando com poesia. São Paulo: Ática, 1990. V. 1 e 2.

BRASIL. Ministério da Educação e do Desporto. BNCC: Base Nacional Comum Curricular para o Ensino Fundamental. Brasília: MEC, 2017. https://doi.org/10.33054/abem2019a4203

BRASIL. Lei 9.394/96, de 20 de dezembro de 1996. Estabelece as diretrizes e bases da educação nacional. Diário Oficial [da] República Federativa do Brasil. Brasília, DF, 23 dez. 1996. https:// doi.org/10.11606/d.2.2017.tde-03102017-105747

CANDIDO, Antônio. Vários Escritos. 5. ed. Rio de Janeiro: Ouro Sobre Azul, 2011.

CANDIDO, Antônio. Literatura e Sociedade. 11. ed. Rio de Janeiro: Ouro Sobre Azul, 2010

CANDIDO, Antônio. 0 direito à literatura. In: CANDIDO, A. Vários Escritos. São Paulo: Duas Cidades, 1995

CANDIDO, Antônio. A Literatura e a Formação do Homem. São Paulo: Duas Cidades, 1972.

CANDIDO, Antônio. O estudo analítico do poema. 3. ed. São Paulo: Humanitas Publicações, 1996.

CAQUI - Revista Brasileira de Haicai. Artigo "Ao professor", em O que é haicai, de 24/08/02. São Paulo, 2002. Disponível em: http://www.kakinet.com/caqui/nyumon40. Acesso em: 03 jun. 2018.

CLEMENT, Rosa. O Haicai e Suas Teorias. Manaus: [S. n.], 2007. Disponível em: http://www. sumauma.net/haicai/haicai-teoria.html. Acesso em: 3 jun. 2018.

COLOMER, Teresa. Andar entre livros: a leitura literária na escola. Trad. Laura Sandroni. São Paulo: Global, 2007.

COSSON, Rildo. Letramento literário: teoria e prática. 2. ed. São Paulo: Contexto, 2014.

COSSON, Rildo. Letramento Literário: teoria e prática. São Paulo: Contexto, 2006 e 2012.

COSSON, Rildo. Círculos de leitura e letramento literário. São Paulo: Contexto, 2014.

COSTA, M. C. C. A leitura de imagens. In: ZILBERMAN, R.; RÖSING, T. M. K. Escola e leitura: velha crise, novas alternativas. São Paulo: Global, 2009.

DYER, Geoff (org.). John Berger para entender uma fotografia. São Paulo: Companhia das Letras, 2017.
FILIPOUSKI, Ana Mariza (org.). Poesia fora da estante. Porto Alegre: L\&PM, 2003.

FONSECA, Pedro Carlos Louzada; SOUSA, Fábio D’Abadia. Literatura e fotografia: o anseio pela apreensão do instante (2008). Disponível em: https://www.revistas.ufg.br/sig/article/ view/5116. Acesso em: mar. 2017. https://doi.org/10.5216/sig.v20i1.5116

FRANCHETTI, Paulo. 2010. Leminski e o Haicai. Sibilia: poesia e crítica literária. http://sibila. com.br/critica/leminski-e-o-haicai/450o. Acesso em: 11 jun. 2018.

GREGORIN FILHO, José Nicolau. Literatura infantil: múltiplas linguagens na formação de leitores. São Paulo: Melhoramentos, 2009.

GOGA, H. Masuda. O haicai no Brasil. São Paulo: Aliança Cultural Brasil-Japão, 1988.

GONÇALVES, Aguinaldo José. Laokoon Revisitado: Relações homológicas entre texto e imagem. São Paulo: Editora da Universidade de São Paulo, 1994. 339 p. https://doi.org/10.11606/ issn.2318-8235.v57iop218-229

KLEIMAN, Angela B. (org.). Os significados do letramento: uma nova perspectiva sobre a prática social a escrita. Campinas, SP: Mercado das Letras, 1995.

KRAUSS, Rosalind. O fotográfico. Barcelona: Editorial Gustavo Gilli, 1990.

LAJOLO, Marisa. Do mundo da leitura para a leitura do mundo. 6. ed. São Paulo: Ática, 2008 https://doi.org/10.17851/2359-0076.13.16.149-150

MARCHUSCHI, Luís Antônio. Produção textual, análise de gêneros e compreensão. São Paulo: Parábola Editorial, 2008.

MATO GROSSO. Secretaria de Estado de Educação de Mato Grosso. Orientações Curriculares Área de Linguagens: Educação Básica. Cuiabá, 2016. https://doi.org/10.20873/uft.25254863.2018v3n2p578

MONTEIRO, Andressa. Como a poesia e a fotografia podem capturar a apreensão de um instante? [2015]. Disponível em: http://jornalggn.com.br/noticia/como-a-poesia-e-a-fotografia-podemcapturar-a-apreensao-de-um-instante. Acesso em: mar. 2017. https://doi.org/10.5380/sclplr. v5i1.68218

NAVAS, Adolfo Montejo. Fotografia \& Poesia: afinidades eletivas. São Paulo: Ubu Editoras, 2017.

PAULINO, Graça; COSSON, Rildo. Letramento literário: para viver a literatura dentro e fora da escola. In: ZILBERMAN, R.; RÖSING, T. M. K. Escola e leitura: velha crise, novas alternativas. São Paulo: Global, 2009. 
PINHEIRO, Helder. Poesia na sala de aula. 2. ed. João Pessoa: Ideia, 2002.

PINHEIRO, Helder. A poesia na sala de aula. 3. ed. Campina Grande: Bagagem, 2007.

PINTO, Júlio Pimentel; TURAZZI, Maria Inez. Ensino de História: diálogos com a literatura e a fotografia. 1. ed. São Paulo: Moderna, 2012.

PRIETO, Heloisa. Conversa de poeta.1. ed. São Paulo: Salamandra, 2003.

ROJO, Roxane; MOURA, Eduardo (org.). Multiletramentos na escola. São Paulo: Parábola Editorial, 2012. https://doi.org/10.18676/cadernoscenpec.v2i1.102

ROJO, Roxane; BARBOSA, Jacqueline P. Hipermodernidade, multiletramentos e gêneros discursivos. 1. ed. São Paulo: Parábola Editorial, 2015. https://doi.org/10.22168/2237-6321.6.6.2.408-413

SANTOS, Leonor Werneck dos; DUARTE, Márcia Nunes. A literatura e o ensino de leitura. In: CONGRESSO NACIONAL DE LINGÜISTICA E FILOLOGIA, 9., 2005, Rio de Janeiro. [Anais eletrônicos...] Rio de Janeiro: 2005. Disponível em: http://www.filologia.org.br/ixcnlf/6/07. htm. Acesso em: 20 maio 2018. https://doi.org/10.17771/pucrio.acad.16477

SIGNORINI, Roberto. A arte do fotográfico. 1. ed. São Paulo: Editora WMF Martins Fontes, 2014.

SOARES, Magda. Letramento: um tema em três gêneros. 2. ed. Belo Horizonte: Autêntica, 2004 https://doi.org/10.11606/d.8.2014.tde-15042015-150006

SOARES, Magda. A escolarização da literatura infantil e juvenil. In: EVANGELISTA, Aracy A.M.; BRANDÃO, Heliana M.B · MACHADO, Maria Z. V. (org.). Escolarização da leitura literária. 2. ed. Belo Horizonte: Autêntica, 2006

SONTAG, Susan. Sobre fotografia. Tradução de Rubens Figueiredo. São Paulo: Companhia das Letras, 2004.

SORRENTI, Neusa. A poesia vai à escola: reflexões, comentários e dicas de atividades. 2.ed. Belo Horizonte: Autêntica, 2009.

SOUZA, Renata Junqueira de (org.). Caminhos para a formação do leitor. São Paulo: DCL, 2004. TODOROV, Tzvetan. A literatura em perigo. Tradução de Caio Meira. Rio de Janeiro: DIFEL, 2009.

VENEROSO, Maria do Carmo de Freitas. A letra como imagem, a imagem da letra. In: NAZARIO, Luiz; FRANCA, Patricia. (org.). Concepções contemporâneas da arte. Belo Horizonte: Editora UFMG, 2006. p. 46-67.
ZILBERMAN, R. A escola e a leitura da literatura. In: ZILBERMAN, R.; RÖSING, T. M. K. Escola e leitura: velha crise, novas alternativas. São Paulo: Global, 2009. 